\title{
O PARADOXO DO MENTIROSO: ASPECTOS TÉCNICOS E FILOSÓFICOS
}

\author{
Guilherme Cardoso ${ }^{1}$ \\ Ederson Melo \\ Túlio Aguiar
}

\begin{abstract}
RESUMO
Nosso objetivo principal, neste texto, é o de fornecer uma introdução crítica ao paradoxo do Mentiroso, tanto do ponto de vista técnico, quanto do ponto de vista filosófico. Primeiramente, vamos apresentar diferentes versões do Mentiroso e relacionar importantes resultados limitativos associados a ele, o Lema Diagonal e o Teorema da Indefinibilidade de Tarski. Em seguida, iremos apresentar algumas das principais abordagens do paradoxo. Finalmente, iremos confrontá-las com uma mesma objeção: a aparente impossibilidade de se conciliar completamente poder expressivo ilimitado de um lado e consistência ou não-trivialidade de outro.
\end{abstract}

Palavras-chave: Paradoxo do Mentiroso. Lema Diagonal. Teorema da Indefinibilidade. Lacunas. Aglutinações. Trivialidade.

\begin{abstract}
Our main goal in this text is to provide a critical introduction to the Liar paradox, both from a technical point of view, as well as from a philosophical point of view. First, we shall present different versions of the Liar and list important limiting results associated with it, the Diagonal Lemma and Tarski's Undefinability Theorem. Next, we shall present some of the main approaches to the paradox. Finally, we shall confront them with the same challenge: the apparent impossibility of completely reconciling unlimited expressive power on the one hand and consistency or non-triviality on the other.
\end{abstract}

Keywords: Liar Paradox. Diagonal Lemma. Undefinability Theorem. Gaps. Gluts. Triviality.

\footnotetext{
${ }^{1}$ Professor do Departamento de Filosofia da Universidade Federal de Ouro Preto.

E-mail: guilherme.cardoso@ufop.edu.br. ORCID:.0000-0003-0045-8508.

2 Professor do Departamento de Filosofia da Universidade Federal do Maranhão.

E-mail: edersonsafra@yahoo.com.br. ORCID: 0000-0003-1706-1128.

${ }^{3}$ Professor do Departamento de Filosofia da Universidade Federal de Minas Gerais.

E-mail: taguiar.bh67@gmail.com. ORCID: 0000-0003-1991-5406.
} 


\section{Introdução}

Para começar, considere o seguinte problema: imagine que você acaba de chegar em uma ilha onde todos os nativos são cavaleiros ou escudeiros. Os cavaleiros são inteiramente honestos e os escudeiros são inteiramente mentirosos; ou seja, tudo que os cavaleiros dizem é verdadeiro e tudo que os escudeiros dizem é falso. Você está à procura de John, um escudeiro da ilha que lhe deve dinheiro. A certa altura, você suspeita que o tenha encontrado, mas não tem certeza, pois John tem dois irmãos gêmeos, James e William. James também é um escudeiro e William é um cavaleiro. Suponha que nessa situação você tenha direito a uma única pergunta com menos de cinco palavras para descobrir se o indivíduo é o John. Qual é a pergunta? A partir de uma breve reflexão, podemos ver que a resposta para a pergunta em questão deveria ser: “você é o James?”. Somente John responderá que sim. James e William, forçosamente, deverão dizer que não. Esse problema foi proposto por Smullyan (1978), como um enigma sobre a verdade. Agora, suponha que John (ou qualquer outro habitante da ilha) afirmasse o seguinte:

(l) $\quad$ Eu sou um escudeiro.

Ora, pelo que sabemos a respeito da ilha, John deve ser um cavaleiro ou um escudeiro. Ele é um cavaleiro se, e somente se, ${ }^{4}$ tudo o que ele diz é verdadeiro, ele é um escudeiro sse tudo o que ele diz é falso. John afirma que é um escudeiro. Por um lado, se a sentença $(l)$ for verdadeira, então John é um escudeiro (é exatamente isso que diz a sentença) e, assim sendo, ( $l$ ) deve ser falsa (já que ela foi dita por um escudeiro que somente profere falsidades). Por outro lado, se a sentença $(l)$ for falsa, então John não é um escudeiro e, como só há escudeiros ou cavaleiros na ilha, John deve ser, então, um cavaleiro e, sendo assim, a sentença deve ser verdadeira (já que ela foi dita por um escudeiro que somente profere falsidades). Portanto, John é um cavaleiro sse ele é um escudeiro, sua afirmação é verdadeira sse sua afirmação é falsa.

Diferentemente do enigma apresentado na abertura do presente texto, o problema de determinar o valor de verdade de $(l)$ não parece ter solução nas

\footnotetext{
${ }^{4}$ Deste ponto em diante, vamos abreviar a expressão "se, e somente se" por "sse".
} 
condições dadas. Nesse sentido, dizemos que o segundo problema é um paradoxo. Especificamente, esse paradoxo pode ser considerado uma versão do paradoxo do Mentiroso, foco do presente artigo.

Um paradoxo pode ser entendido como um argumento aparentemente aceitável que conduz, através de premissas (ou pressuposições) aparentemente aceitáveis, a uma conclusão aparentemente inaceitável. Nessa perspectiva, dizemos que um paradoxo surge quando somos levados para o aparentemente inaceitável partindo do aparentemente aceitável (cf. READ, 1995, p.193 e SAINSBURY, 2009, p.1).

Uma solução rápida e aceitável do paradoxo do escudeiro consiste em simplesmente recusar sua existência. Uma ilha que satisfaça rigorosamente tais condições simplesmente não existe, ela é tão plausível quanto o cavalo branco que não é branco. Como veremos em seguida, uma família de paradoxos pode ser associada ao Escudeiro, a família do paradoxo do Mentiroso.

Como veremos neste artigo, há várias versões do paradoxo do Mentiroso que não permitem uma solução tão simples. Particularmente, várias abordagens dadas ao paradoxo do Mentiroso surgem ao propor algum tipo de revisão dos pressupostos envolvidos. Ainda que possamos tratar os paradoxos de maneira lúdica, como no exemplo do Escudeiro, alguns paradoxos podem revelar problemas fundamentais sobre os conceitos envolvidos.

Nesta área da Lógica e da Filosofia, tão importantes quanto os próprios paradoxos são as ricas abordagens e técnicas elaboradas no intuito de resolvê-los. Além disso, importantes técnicas semânticas e importantes resultados metalógicos foram estabelecidos como consequência dos limites estabelecidos por estes paradoxos em teorias formais.

Tendo isso em vista, o presente artigo tem como objetivo apresentar uma introdução crítica ao paradoxo do Mentiroso (ou, simplesmente, Mentiroso), destacando os principais resultados técnicos a ele relacionados, as principais abordagens propostas ao paradoxo e levantando algumas reflexões filosóficas relacionadas.

Na seção 2, vamos expor os pressupostos envolvidos no Mentiroso a partir de suas principais versões, reunidas no conjunto de paradoxos que cha- 
mamos aqui de "família do mentiroso". Na seção 3, veremos que as versões do Mentiroso apresentadas na seção 2 estão apoiadas em resultados formais importantes, geralmente estudados em cursos de metalógica. Especificamente, iremos conferir o Lema da Diagonal e o Teorema da Indefinibilidade de Tarski. Feito isso, na seção 4, iremos apresentar algumas das principais abordagens filosóficas do Mentiroso. Particularmente, vamos expor três influentes tratamentos dados a ele. Começaremos pela abordagem de Tarski que lida com o Mentiroso através de uma hierarquias de linguagens. Posteriormente, veremos a abordagem de Kripke que admite lacunas (gaps) de valores de verdade (i.e. sentenças que não são nem verdadeiras e nem falsas). Por fim, vamos conferir a abordagem dialeteísta dada por Priest que assume aglutinações (gluts) de valores de verdade (i.e. sentenças que são tanto verdadeiras quanto falsas). Ao longo da seção 4 vamos indicar que as abordagens dadas ao Mentiroso, inclusive a dialeteísta, restringem o poder expressivo da linguagem de uma maneira ou outra e que, portanto, a resiliência do Mentiroso está relacionada com o limite expressivo das linguagens em que ele ocorre.

\section{A Família do Mentiroso}

Nesta seção, iremos apresentar informalmente as principais versões do Mentiroso, apontando seus pressupostos.

A versão simples do Mentiroso, também conhecida como Mentiroso Simples, pode ser exemplificada por qualquer sentença autorreferencial que atribui a si mesma o predicado "é falsa". Considere, por exemplo, a seguinte sentença:

(1) (1) é falsa.

(1) é uma sentença que diz de si mesma que é falsa. ${ }^{5}$ Se (1) é verdadeira, o que ela diz é o caso, então (1) é falsa. Se, por outro lado, (1) é falsa, o que ela diz é o caso, então ela é verdadeira. (1) é verdadeira sse (1) é falsa. Logo, (1) é verdadeira e falsa. Dois pressupostos fundamentais acerca do conceito de

\footnotetext{
${ }^{5}$ Existem outros mecanismos disponíveis na linguagem natural para produzir sentenças autorreferenciais. Por exemplo, poderíamos dizer que a sentença em itálico na nota 5 do presente texto é falsa.
} 
verdade estão implícitos no presente argumento, o Princípio de Bivalência (PB) e a Transparência da Verdade (ou Esquema T):

(PB) Toda sentença é verdadeira ou falsa.

(T) Uma sentença é verdadeira sse o que ela diz é o caso.

À primeira vista, pode-se supor que a rejeição do (PB) seja completamente suficiente para resolver o Mentiroso. Esta é uma suposição apressada, como fica claro pela apresentação de uma versão mais forte do Mentiroso, o Mentiroso Reforçado:

(2) (2) não é verdadeira.

Na medida em que se rejeita o (PB), algumas sentenças não são verdadeiras nem falsas. Classicamente, "falsa" e "não-verdadeira" são predicados co-extensionais. Esse tipo de rejeição do (PB) é normalmente identificado como truth value gaps (lacunas de valores-verdade). Entretanto, apenas classificar (2) como nem verdadeira nem falsa não resolve o problema. Afinal, se (2) não é verdadeira nem falsa, a fortiori (2) não é verdadeira, confirmando aquilo que é dito por (2). O novo paradoxo pressupõe não o (PB), mas o Princípio do Terceiro Excluído (PTE); que de toda sentença, ela ou sua negação é verdadeira. Novamente, por (T), (2) é verdadeira sse (2) não é verdadeira. Logo, pelo (PTE), (2) é verdadeira e (2) não é verdadeira.

Nas versões anteriores, os paradoxos foram obtidos por meio de sentenças que referiam-se a si mesmas, sentenças autorreferenciais. Entretanto, algumas versões do Mentiroso podem ser também engendradas por ciclos de referência, como exemplificado pelo paradoxo do Cartão Postal: 
(3) (4) é verdadeira.

(4) (3) não é verdadeira.

Note que neste caso não temos autorreferência, mas ainda temos algum tipo de circularidade sob a relação de referir, (3) se refere a (4) que, por sua vez, refere-se a (3). Por argumentos análogos aos anteriores, podemos verificar que (3) e (4) também não admitem avaliações consistentes.

A circularidade presente em (1), (2), (3) e (4) parece depender de certas circunstâncias empíricas e extrínsecas em relação às sentenças elas mesmas. Entretanto, como veremos mais tarde (por meio do Lema Diagonal), é possível garantir a existência desse tipo de circularidade mesmo em cenários muito bem arregimentados.

A próxima versão, conhecida como paradoxo de Yablo, ${ }^{6}$ aparenta dispensar todo tipo de circularidade ou autorreferência. Neste caso, vamos precisar de uma lista com infinitas sentenças:

$\left(5_{1}\right)$ Para todo $x>1,\left(5_{x}\right)$ não é verdadeira.

$\left(5_{2}\right) \quad$ Para todo $x>2,\left(5_{x}\right)$ não é verdadeira.

$\left(5_{3}\right) \quad$ Para todo $x>3,\left(5_{x}\right)$ não é verdadeira.

$\left(5_{n}\right) \quad$ Para todo $x>n,\left(5_{x}\right)$ não é verdadeira.

$\left(5_{n+1}\right)$ Para todo $x>n+1,\left(5_{x}\right)$ não é verdadeira.

Suponha que $\left(5_{k}\right)$ é verdadeira (para qualquer $k>0$ ). Assim, para todo $x>k$, $\left(5_{x}\right)$ não é verdadeira, pois é isto mesmo que $\left(5_{k}\right)$ diz. Consequentemente, $\left(5_{k+1}\right)$ não é verdadeira. Ora, se $\left(5_{k+1}\right)$ não é verdadeira, então, para algum $y>k+1,\left(5_{y}\right)$ é verdadeira, logo, $\left(5_{k}\right)$ não é verdadeira. Portanto, nenhuma sentença da lista pode ser consistentemente avaliada como verdadeira, nenhuma delas é verdadeira. Isto implica que, para qualquer $x>k,\left(5_{x}\right)$ não é verdadeira, qualquer que seja $k>0$. Logo, $\left(5_{k}\right)$ é verdadeira, qualquer que seja $k>0$.

${ }^{6}$ Inicialmente proposta por Yablo (1993). 
Em suma, todas as sentenças da lista são verdadeiras e nenhuma delas é verdadeira.

O paradoxo de Yablo sugere que a circularidade pode não ser um requisito necessário para a obtenção dos paradoxos. ${ }^{7}$ Veremos agora que a circularidade também não é, alegadamente, um requisito suficiente para a obtenção dos paradoxos. Algumas sentenças podem engendrar circularidade sob a relação de referir, sem contudo derivar paradoxos. Considere as seguintes sentenças:

(6) (6) é um exemplo de autorreferência.

(7) (7) contém menos de vinte palavras.

(8) (8) é verdadeira.

As três últimas sentenças não parecem engendrar paradoxos. Ao menos, não parece haver razões que nos impedissem de avaliá-las consistentemente como verdadeiras ou falsas. (6) e (7) são intuitivamente verdadeiras. Quanto a (8), não há qualquer critério para decidir se ela é verdadeira ou falsa. De todo modo, ela pode ser avaliada tanto como verdadeira quanto como falsa, sem que isto implique uma contradição. Na literatura, (8) é conhecida como Truth Teller. O valor de (8) é frequentemente classificado como up for grabs ou, simplesmente, como um valor em disputa, ou arbitrário.

Algumas versões do Mentiroso podem depender de fatores contingentes e extrínsecos às sentenças elas mesmas. Assim, existem sentenças que envolvem essencialmente circularidade, mas que podem ou não engendrar paradoxos, a depender de fatores extrínsecos. Estas versões são conhecidas como Mentirosos Contingentes. Exemplo:

(9) (9) é falsa e não existe vida em Trappist-1.

Ora, se (9) é verdadeira, então, as duas sentenças que a compõem devem ser verdadeiras. Assim, (9) não pode ser verdadeira (é falsa). Por outro lado, se ao

\footnotetext{
${ }^{7}$ Isso não é consensual. Pode-se argumentar que cada uma das sentenças na lista infinita de Yablo é autorreferencial. Grosso modo, se cada uma das sentenças diz de todas as seguintes que elas não são verdadeiras, então cada uma delas tem um componente indexical que só pode ser preenchido por referência à sentença ela mesma. Cada sentença diz algo como "todas as sentenças seguintes a esta própria sentença são não-verdadeiras".
} 
menos uma de suas componentes é falsa, (9) é falsa. Suponha que existe vida em Trappist-1. Neste caso, (9) é simplesmente falsa. Isto torna verdadeira a primeira componente de (9), mas não torna verdadeira (9), ela mesma. Alternativamente, se não existe vida em Trappist-1, (9) é verdadeira sse (9) é falsa. Portanto, o valor semântico de (9) depende de fatos contingentes e extrínsecos à sentença ela mesma. Se houver vida em Trappist-1, (9) é falsa, de outro modo, (9) é paradoxal.

Assim como podemos utilizar a conjunção e outros conectivos ou quantificadores para formar novos mentirosos contingentes, podemos também utilizar os conectivos e quantificadores para construir versões do paradoxo de Curry. A especificidade do Curry é que ele coloca diretamente uma ameaça de trivialidade para as teorias. ${ }^{8}$ Considere o seguinte exemplo:

(10) Se (10) é verdadeira, então todas as sentenças são verdadeiras.

Pela interpretação clássica da condicional, (10) não pode ser avaliada consistentemente como falsa, pois se (10) é falsa, sua antecedente é verdadeira e sua consequente é falsa e, assim, (10) é verdadeira e falsa. Por outro lado, se (10) é verdadeira, então, a sentença antecedente de (10) também é verdadeira, pois é isso mesmo que ela diz. Por Modus Ponnens (MP), todas as sentenças são verdadeiras. Vimos que, sob a hipótese de que (10) é verdadeira, então todas sentenças são verdadeiras. Ora, isto é exatamente o que (10) diz. Isso é uma demonstração da verdade de (10). ${ }^{9}$ Logo, por (MP), todas as sentenças são verdadeiras. Note que poderíamos substituir a consequente de (10) por qualquer sentença da linguagem em questão e o mesmo argumento poderia ser utilizado como uma demonstração desta sentença.

O paradoxo de Curry desempenha, em relação à estratégia de aglutinações, um papel análogo ao que o Mentiroso Reforçado desempenha em relação à estratégia de lacunas. A estratégia de aglutinações consiste em admitir

\footnotetext{
${ }^{8}$ Classicamente, inconsistência implica trivialidade, pelo Princípio de Explosão (PE). O paradoxo de Curry ameaça de trivialidade mesmo aquelas teorias que rejeitam o (PE), as teorias paraconsistentes.

${ }^{9}$ Formalmente, esse passo é desempenhado pelo Teorema da Dedução (TD) (ou Prova Condicional). Em alguns contextos, o mesmo argumento pode ser formalizado por meio da Contração (Con).
} 
que algumas sentenças são concomitantemente verdadeiras e falsas (truthvalue gluts). O paradoxo de Curry mostra que, nestes casos, se ainda valem certas propriedades da condicional, como (MP) e (Con) ou (TD), a trivialidade não pode ser evitada.

Existem muitas outras versões do Mentiroso, mas seria impossível introduzir de forma exaustiva toda esta família de paradoxos. Tendo apresentado informalmente as principais versões, tentaremos agora precisar um pouco melhor os principais resultados formais que fundamentam estes argumentos.

\section{Aspectos formais}

Os paradoxos acima apresentados estão apoiados em certos resultados formais estudados em cursos de Metalógica. ${ }^{10}$ Nesta seção, iremos apresentar alguns destes resultados. Iremos apresentar o Lema Diagonal e o Teorema da Indefinibilidade de Tarski. O Lema Diagonal garante a possibilidade de reconstruir, em teorias formais, sentenças autorreferenciais (ou que se comportam logicamente como sentenças autorreferenciais). $\mathrm{O}$ Teorema da Indefinibilidade estabelece um limite rigoroso para tais teorias. Grosso modo, uma teoria formal que satisfaça as condições do Lema Diagonal não pode conter o seu próprio predicado-verdade, nenhum dos seus predicados define o conjunto de todas as sentenças verdadeiras da própria teoria. Este importante resultado foi estabelecido pelo filósofo, lógico e matemático polonês Alfred Tarski.

Uma teoria é um conjunto de sentenças $\Gamma$ fechado sob a relação de consequência lógica sintática, ou seja, $A \in \Gamma$, se $\Gamma \vdash A$ (para qualquer sentença $A$ da linguagem da teoria). Note que, dado qualquer conjunto de sentenças $\Gamma$ de uma linguagem $L$, o conjunto das suas consequências dedutivas (teoremas), $T H(\Gamma)$, é uma teoria nesta linguagem. Dizemos que uma teoria $\Sigma$ (na linguagem $L$ ) é recursivamente axiomatizável, se existe um conjunto recursivo de sentenças $\Gamma$ de $L$, tal que, $T H(\Gamma)=\Sigma .^{11}$

\footnotetext{
${ }^{10} \mathrm{O}$ leitor pode encontrar uma exposição mais detalhada destes resultados em Boolos at al (2007) e também em Cardoso (2018).

${ }^{11}$ Pela Tese Church-Turing, as funções recursivas (equivalentemente, as funções computáveis por máquinas de turing) são exatamente as funções efetivamente computáveis, aquelas que podem ser computadas por algoritmos. A função característica de um conjunto determi-
} 
Uma teoria $\Sigma$ é inconsistente sse existe uma sentença $A$ da linguagem de $\Sigma$, tal que, $\Sigma \vdash A \wedge \neg A$. $\Sigma$ é consistente sse $\Sigma$ não é inconsistente. Uma teoria $\Sigma$ é trivial sse, para toda sentença $B$ da linguagem de $\Sigma, \Sigma \vdash B$. Pelo (PE), se $\Sigma$ é inconsistente, $\Sigma$ é trivial. Por outro lado, se $\Sigma$ é trivial, então, $\Sigma$ prova todas as sentenças da sua linguagem. Logo, a fortiori, $\Sigma$ é inconsistente. Logo, $\Sigma$ é inconsistente sse $\Sigma$ é trivial.

\subsection{O Lema Diagonal}

Os resultados limitativos que iremos apresentar a seguir dizem respeito a um tipo especial de teorias, aquelas que são capazes de representar todas as funções recursivas. Grosso modo, isso permite que tais teorias sejam capazes de emular as sentenças paradoxais exemplificadas na seção 2. Como exemplos paradigmáticos, veremos que algumas teorias aritméticas (todas as extensões da Aritmética de Robinson - Q) satisfazem este requisito. ${ }^{12}$

As sentenças paradoxais exemplificadas na seção anterior não são sentenças aritméticas. A princípio, sentenças aritméticas envolvem termos para números e operações como soma, multiplicação, etc. Como podemos, então, dizer que é possível de algum modo emular as sentenças paradoxais mencionadas? Ora, sabidamente, o poder expressivo da Aritmética reside em seu potencial representativo. Por meio de codificações, podemos representar muitas outras coisas com as sentenças aritméticas. Em particular, todas as funções recursivas são representáveis em todas as extensões de Q.

A linguagem da Aritmética é definida pelo seguinte conjunto de símbolos não lógicos: $\{0, s,+, \times,<\}$. A interpretação (modelo) padrão dessa linguagem toma como domínio o conjunto dos números naturais, interpreta $s$ como a função de sucessor, $+\mathrm{e} \times$ como as operações de soma e multiplicação e $<$ como a relação de ordem estrita "menor que". O conjunto de todas as sen-

na, para todo $x$, se $x$ pertence ou não a este conjunto. O conjunto é recursivo sse a sua função característica é recursiva. Isso é uma simplificação. Para mais detalhes, ver Boolos et al (2007).

${ }^{12}$ Q é também conhecida como Aritmética Minimal. Ela é forte o suficiente para representar todas as funções recursivas, mas fraca o suficiente para não autorizar as generalizações obtidas por provas indutivas (Q não tem um axioma de indução). Esta é a principal diferença entre Q e sua mais famosa extensão, a Aritmética de Peano - PA. O leitor pode encontrar uma apresentação de Q e também de PA em Boolos et al (2007, cap.16). 
tenças da linguagem da Aritmética que são verdadeiras no modelo padrão é a teoria conhecida como Aritmética Verdadeira (V). Um dos resultados que veremos a seguir diz exatamente que $\mathrm{V}$ não é recursivamente axiomatizável.

Antes de falar em representabilidade, precisamos adotar algum esquema de codificação. A seguinte correspondência $c$ entre números e símbolos primitivos na linguagem da Aritmética é o primeiro passo. Vamos nos restringir a representar funções sintáticas definidas sobre expressões da própria linguagem da Aritmética. De outro modo, teríamos de incluir mais coisas nesse esquema de codificação:

\begin{tabular}{|c|c|c|c|c|c|c|c|c|c|c|c|c|}
\hline( & ) &, & $\neg$ & $\vee$ & $\exists$ & $=$ & $x_{i}$ & $<$ & 0 & $s$ & + & $\times$ \\
\hline 1 & 3 & 5 & 7 & 9 & 11 & 13 & $2.5^{i}$ & 36 & 8 & 24 & 72 & 360 \\
\hline
\end{tabular}

O esquema acima, portanto, permite relacionar cada símbolo primitivo da linguagem da Aritmética com um único número e cada sequência de símbolos com uma única sequência de números. Isso é suficiente para obter uma função que leve de sequências de símbolos a números, a função número de gödel:

$$
g n\left(\left(s_{0}, s_{1}, \ldots, s_{n-1}\right)\right)=2^{n} \times\left(\prod_{i=1}^{n-1}\left(\pi(i)^{c\left(s_{i-1}\right)}\right)\right)
$$

Onde $\pi$ é uma função que leva de números inteiros a números primos, uma enumeração dos primos. A função $c$, também utilizada na definição, é aquele esquema de correspondência descrito na tabela acima. Assim, $c\left(s_{i-1}\right)$ nos dá o número que corresponde ao símbolo que aparece na posição $i-1$ da sequência de símbolos. Este método de codificação está baseado no fato de que todo número natural tem uma única decomposição em fatores primos. Cada fórmula nos dá uma sequência de símbolos. Primeiramente, detectamos o cumprimento da fórmula (quantidade de símbolos) na posição de expoente do número 2. Uma sequência do tipo $\left(s_{0}, s_{1}, \ldots, s_{n-1}\right)$ tem $n$ termos. Depois, os símbolos são listados nas respectivas posições de expoentes dos primos. Assim, por exemplo, a fórmula $\neg \exists x_{0}\left(x_{0}<0\right)$ será codificada pelo número: 


$$
2^{8} \times 3^{7} \times 5^{11} \times 7^{2} \times 11^{1} \times 13^{2} \times 17^{36} \times 19^{8} \times 23^{3}
$$

Este é o seu número de gödel. Note que números são objetos do domínio de modelos da linguagem da Aritmética. $\mathrm{O}$ modo de se referir indiretamente, portanto, aos objetos codificados por números de gödel é através dos respectivos numerais, estes sim termos da linguagem da Aritmética. Vamos distinguir números de numerais por meio da notação em negrito. Assim, 0 é o numeral que denota, na interpretação padrão, o número zero. ${ }^{13}$ Ademais, $\ulcorner e\urcorner$ é o numeral do número de gödel da expressão $e$.

Todavia, para que sejamos capazes de falar indiretamente sobre fórmulas na linguagem da Aritmética é antes necessário que possamos representar as funções e relações definidas sobre elas. Por exemplo, para dizer que $\neg(s(0)<0)$ é o resultado de se substituir todas as ocorrências de $x_{0}$ por $s(0)$ na fórmula $\neg\left(x_{0}<0\right)$, temos também de representar a relação entre estas expressões, não basta codificá-las. Isto nos leva diretamente à definição seguinte.

Representabilidade: seja $f$ uma função de aridade $n$ e $\Sigma$ uma teoria aritmética de primeira ordem. Assim, $f$ é representável em $\Sigma$ sse existe uma fórmula $\Phi$ (de aridade $n+1$ ) na linguagem da Aritmética, tal que,

$$
f\left(k_{1}, \ldots, k_{n}\right)=m \text { sse } \Sigma \vdash \forall y\left(\Phi\left(\left\ulcorner k_{1}\right\urcorner, \ldots,\left\ulcorner k_{n}\right\urcorner, y\right) \leftrightarrow y=\ulcorner m\urcorner\right)^{14}
$$

Definibilidade é a contraparte semântica da noção de representabilidade. No caso das teorias aritméticas, diremos que a função $f$ é aritmeticamente definível sse $f$ é representável em V. Ou seja, $f\left(k_{1}, \ldots, k_{n}\right)=m$ sse $\Phi\left(\left\ulcorner k_{1}\right\urcorner, \ldots,\left\ulcorner k_{n}\right\urcorner,\ulcorner m\urcorner\right)$ é verdadeira no modelo padrão da linguagem da Aritmética.

Como dissemos antes, todas as funções recursivas são representáveis nas extensões de Q, portanto, de acordo com a Tese Church-Turing, todas as funções efetivamente computáveis são representáveis em Q. Estamos particu-

\footnotetext{
${ }^{13}$ Para facilitar a leitura de fórmulas, quando o contexto não produzir ambiguidade entre número e numeral, vamos evitar a utilização de negrito.

${ }^{14}$ Podemos também dizer que uma relação $R$ é representável em uma teoria sse sua função característica é representável nessa teoria.
} 
larmente interessados em um grupo de funções, aquelas funções sintáticas necessárias para a construção de sentenças autorreferenciais.

A função sintática que iremos utilizar para a construção de autorreferência é a diagonal. A diagonal de $A$ é $\exists x(x=\ulcorner A\urcorner \wedge A)$. Dada a codificação por números de gödel introduzida anteriormente, podemos utilizar a função numérica associada, diag $(x)$, que leva de números para números, de $g n(A)$ para $g n(\exists x(x=\ulcorner A\urcorner \wedge A))$, por exemplo. Não é difícil ver que $\operatorname{diag}(g n(A))$ é efetivamente computável (para qualquer fórmula $A$ ). Grosso modo, o procedimento consiste em formar o número de gödel de $A$, o seu numeral e encaixá-los na codificação do número de gödel da diagonal de $A$. Portanto, existe uma fórmula, $\operatorname{Diag}(x, y)$, na linguagem da Aritmética, tal que, $\operatorname{diag}(n)=k$ sse $Q \vdash \forall y(\operatorname{Diag}(n, y) \leftrightarrow y=k)$. Isso é suficiente para demonstrar o resultado que garante a existência de sentenças autorreferenciais em todas as extensões de Q, o Lema Diagonal (LD):

Lema Diagonal: seja $\Sigma$ uma teoria de primeira ordem que representa todas as funções recursivas e $B(x)$ uma fórmula qualquer da sua linguagem. ${ }^{15}$ Assim, existe uma sentença $G$, tal que,

$$
\Sigma \vdash G \leftrightarrow B(\ulcorner G\urcorner)
$$

Demonstração: considere a fórmula $\exists y(\operatorname{Diag}(x, y) \wedge B(y))$, abreviadamente, $F$. Compute agora a diagonal de $F$. Obtemos assim a sentença $G$ :

$$
\exists x(x=\ulcorner F\urcorner) \wedge \exists y(\operatorname{Diag}(x, y) \wedge B(y))
$$

Grosso modo, a sentença $G$ diz que existe uma diagonal de $F$ e que ela satisfaz $B$. A diagonal de $F$, entretanto, é a sentença $G$, ela mesma. Assim, $G \operatorname{diz}$ de si mesma que ela é $B$. Classicamente, isto implica que i) $\Sigma \vdash G \leftrightarrow \exists y(\operatorname{Diag}(\ulcorner F\urcorner, y) \wedge B(y))$. Além disso, a representabilidade de diag garante que ii) $\Sigma \vdash \forall y(\operatorname{Diag}(\ulcorner F\urcorner=y) \leftrightarrow y=\ulcorner G\urcorner)$. Logo, por i e ii,

\footnotetext{
15 Por razões didáticas, estamos considerando uma versão mais simples do (LD) e nos restringindo às fórmulas nas quais apenas uma variável ocorre livre.
} 
$\Sigma \vdash G \leftrightarrow \exists y(y=\ulcorner G\urcorner \wedge B(y))$. Por sua vez, isso implica classicamente que $\Sigma \vdash G \leftrightarrow B(\ulcorner G\urcorner) .{ }^{16}$

Assim, todas as teorias que sejam capazes de representar as funções recursivas incluem sentenças autorreferenciais. Como vimos, a função diagonal é efetivamente computável e, pela Tese Church-Turing, todas as funções efetivamente computáveis são recursivas. Todas as funções recursivas são representáveis em todas as extensões de Q. Logo, todas as extensões de Q incluem sentenças autorreferenciais. Veremos em breve que isto impõe importantes limites para teorias aritméticas, limites relacionados diretamente aos paradoxos apresentados na primeira parte. Antes, precisamos introduzir o Esquema T.

\subsection{O Esquema T}

Vamos tratar adiante de outra importante propriedade de teorias que precisa ser previamente definida, a propriedade de conter o seu próprio predicado-verdade. Grosso modo, uma teoria que contém seu próprio predicadoverdade é uma teoria que permite expressar fatos acerca da verdade ou falsidade das sentenças da própria linguagem na qual é formulada. De modo mais rigoroso, uma teoria $\Sigma$ contém seu próprio predicado-verdade sse: i) Existe um predicado $T(x)$ na linguagem de $\Sigma$, tal que, para toda sentença $A$ na linguagem de $\Sigma$, existe um termo $\ulcorner A\urcorner$ de $\Sigma$ que representa um nome de $A$ em $\Sigma$. ii) $\Sigma$ acarreta todas as instâncias do Esquema T, qual seja:

$$
T(\ulcorner A\urcorner) \leftrightarrow A
$$

Em Tarski (1935) e Tarski (1944), o Esquema T é parte essencial da caracterização de um predicado-verdade. O Esquema T garante que o predicado em questão seja de fato um predicado-verdade, ou seja, é satisfeito por todas, e somente, as sentenças verdadeiras da linguagem. Neste sentido, dizemos ainda que o Esquema $\mathrm{T}$ garante a adequação material do predicado. Co-

\footnotetext{
${ }^{16}$ A demonstração resumida acima leva em consideração a pobreza de termos da linguagem da Aritmética. Para uma versão mais intuitiva do (LD), considere a seguinte versão análoga de função diagonal: $\operatorname{diag} *(A)=A(\ulcorner A\urcorner)$. Considere a fórmula $F$ seguinte: $B(\operatorname{diag} *(x))$. Compute $\operatorname{diag} *(F)$, obtendo a sentença $G$, qual seja, $B(\operatorname{diag} *(\ulcorner B(\operatorname{diag} *(x))\urcorner))$. Note que a sentença $\mathrm{G}$ diz que a diagonal de $\mathrm{F}$ é $\mathrm{B}$, mas a diagonal de $\mathrm{F}$ é a sentença $\mathrm{G}$, ela mesma.
} 
mo apontado em Haack (1978, pp.144-145), dada uma linguagem $L$ e duas definições alternativas de verdade para as sentenças de $L, D_{1}$ e $D_{2}$, se ambas forem materialmente adequadas, ambas terão exatamente a mesma extensão. ${ }^{17}$

Tarski obteve importantes resultados positivos na construção de definições de verdade. Tais definições estão limitadas por um resultado negativo igualmente importante, o Teorema da Indefinibilidade. Grosso modo, o teorema de Tarski impõe certos limites ao poder expressivo de linguagens, limites especialmente relacionados aos requisitos para o fechamento semântico de uma linguagem. Uma linguagem é semanticamente fechada sse ela é capaz de expressar os fatos relativos à sua própria semântica (interpretação). Uma linguagem semanticamente fechada deve conter seu próprio predicado verdade e acarretar todas as instâncias do Esquema T. Como veremos a seguir, Esquema T e (LD) são conjuntamente inconsistentes.

\subsection{O Teorema da Indefinibilidade}

O Teorema da Indefinibilidade (TI) foi demonstrado primeiramente por Tarski (1935). Embora Tarski não utilize a terminologia e os métodos aqui esboçados, demonstra essencialmente o mesmo resultado. A ideia é que se uma teoria é forte o suficiente para satisfazer os requisitos do (LD), então ela não pode consistentemente conter o seu próprio predicado-verdade.

Teorema da Indefinibilidade: Seja $\Sigma$ uma teoria de primeira ordem clássica que representa todas as funções recursivas. Assim, se $\Sigma$ é consistente, $\Sigma$ não pode conter o seu próprio predicado-verdade.

Demonstração: suponha que $\Sigma$ é uma teoria que contém o seu próprio predicado-verdade. Assim, existe um predicado $T(x)$ na linguagem de $\Sigma$, tal que, para toda sentença $A$ na linguagem de $\Sigma, \Sigma \vdash T(\ulcorner A\urcorner) \leftrightarrow A$, ou seja, $\Sigma$ acarreta todas as instâncias do Esquema T. Pelo (LD), se $\Sigma$ representa todas as funções recursivas e $T(x)$ é uma fórmula da sua linguagem, então, existe uma sentença $G$ da sua linguagem, tal que, $\Sigma \vdash G \leftrightarrow \neg T(\ulcorner G\urcorner)$ (se $T(x)$ é fórmu-

\footnotetext{
17 Tarski toma por linguagens sistemas formais, ou seja, linguagens formais interpretadas e acompanhadas de um conjunto de axiomas e regras de derivação.
} 
la, $\neg T(x)$ é fórmula). Pelo Esquema T, $\Sigma \vdash T(\ulcorner G\urcorner) \leftrightarrow G$. Pela transitividade da bicondicional, $\Sigma \vdash T(\ulcorner G\urcorner) \leftrightarrow \neg T(\ulcorner G\urcorner)$. Logo, $\Sigma$ é inconsistente. ${ }^{18}$

Outro modo de enunciar o Teorema de Tarski recorre à noção de definibilidade aritmética. Pelo que vimos anteriormente, o conjunto das sentenças verdadeiras da linguagem da Aritmética no modelo padrão é aritmeticamente definível sse existe uma fórmula $T(x)$ na linguagem da Aritmética, tal que, $A$ é verdadeira no modelo padrão (ou seja, $V \vdash A$ ) sse $T(\ulcorner A\urcorner)$ é verdadeira no modelo padrão (ou seja, $V \vdash T(\ulcorner A\urcorner$ ), pois vimos que definibilidade aritmética equivale a representabilidade em V), para qualquer sentença $A$ da linguagem da Aritmética. Assim, o conjunto das sentenças verdadeiras no modelo padrão é aritmeticamente definível sse $V \vdash A \leftrightarrow T(\ulcorner A\urcorner)$, para toda sentença $A$ da linguagem. Entretanto, $V$ é uma extensão de Q, portanto representa todas as funções recursivas. Por (LD), existe uma sentença $G$, tal que, $V \vdash G \leftrightarrow \neg T(\ulcorner G\urcorner)$. Por redução, concluímos que o conjunto das sentenças verdadeiras da linguagem da Aritmética no modelo padrão não é aritmeticamente definível (não é representável em V). Isto significa, entre outras coisas, que V não é recursivamente axiomatizável e que, portanto, as teorias aritméticas humanamente manuseáveis são incompletas (existem sentenças aritméticas que elas não podem demonstrar nem refutar).

Como dissemos antes, (TI) espelha os mentirosos em um cenário estritamente formal. A ideia é que os mentirosos resultam de certas aplicações do (LD) em teorias semanticamente fechadas (ou seja, teorias que contenham seu próprio predicado de verdade). A sentença $G$ introduzida na prova do teorema funciona exatamente como uma versão do Mentiroso Reforçado. Incentivamos o leitor a verificar como as outras versões seriam formalizadas.

\section{Abordagens filosóficas}

O Teorema da Indefinibilidade de Tarski, como vimos, não é um paradoxo, mas um resultado formal a respeito do conceito de verdade. Todavia, este teorema identifica certos limites que espelham intuitivamente os argu-

\footnotetext{
${ }^{18}$ Se uma teoria demonstra $A \leftrightarrow \neg A$, então ela é inconsistente. Aliás, este fato pode ser demonstrado sem pressupor o (PTE) ou qualquer outra regra não intuicionista, apenas Consequentia Mirabilis.
} 
mentos anteriormente classificados como paradoxos. Não é claro, entretanto, qual seja exatamente a lição que podemos extrair do teorema de Tarski acerca dos paradoxos.

Grosso modo, o teorema de Tarski nos diz que uma teoria semanticamente fechada e clássica será também inconsistente. Nestas circunstâncias, como vimos, o Lema Diagonal estabelece a existência de sentenças mentirosas, como as sentenças (1)-(5) da segunda seção. Na presença de tais sentenças, do Esquema $\mathrm{T}$ e da Lógica Clássica, somos levados à inconsistência e à trivialidade.

Mesmo as teorias aritméticas mais fracas, como vimos, satisfazem os antecedentes do Lema Diagonal. Neste caso, as sentenças paradoxais funcionam como provas por redução ao absurdo da indefinibilidade, tais teorias não são semanticamente fechadas, não possuem seu próprio predicado-verdade. E quanto à linguagem natural? Podemos extrair alguma lição desse resultado formal para a linguagem natural?

A linguagem natural está contaminada de ambiguidades, vagueza e todo tipo de imprecisão que inviabiliza a sua formalização. A conclusão de Tarski neste ponto é bastante prudente:

Nossa linguagem cotidiana não é, com certeza, uma linguagem com uma estrutura especificada com exatidão. Não sabemos precisamente quais expressões são sentenças, e sabemos em grau ainda menor quais sentenças devem ser tomadas como afirmáveis. Assim, o problema da consistência não tem um significado exato com respeito a essa linguagem. No melhor dos casos, podemos apenas arriscar o palpite de que uma linguagem cuja estrutura tenha sido exatamente especificada, e que se assemelhe à nossa linguagem cotidiana o mais possível, seria inconsistente (TARSKI, [1944], 2006, p. 170).

A linguagem natural não é uma linguagem formal, mas podemos certamente tentar construir linguagens e teorias que espelhem (ainda que parcialmente) o conceito ordinário de verdade. Como vimos, não existe uma teoria clássica e consistente que contenha o seu próprio predicado-verdade e represente todas as funções recursivas. A questão que podemos nos colocar agora é: estes requisitos são todos essenciais para o conceito ordinário de verdade? Este é o problema filosófico levantado pelos mentirosos. Diferentes tentativas de resolver o paradoxo pretendem argumentar contra um ou mais destes re- 
quisitos, revisando de algum modo nossa compreensão acerca da linguagem natural e do conceito ordinário de verdade. Existe uma literatura imensa de tentativas de solução ao paradoxo do Mentiroso. Não pretendemos sequer esboçar aqui uma classificação desta literatura. No que segue iremos apenas tecer breves comentários sobre as principais famílias de soluções. ${ }^{19}$

As abordagens hierárquicas são baseadas em hierarquias geradas pelas restrições impostas pelo (TI). O predicado-verdade de uma linguagem $L$ pode ser introduzido na sua metalinguagem $M L$, desde que $M L$ seja essencialmente mais rica do que $L$, ou seja, desde que $L$ não seja capaz de expressar $M L$ em si mesma. Teremos assim, uma hierarquia de linguagens, onde o predicado verdade de cada linguagem é sempre introduzido na sua metalinguagem. Para dar um exemplo, considere a linguagem da Aritmética de primeira ordem na interpretação padrão. Assim, teremos a seguinte hierarquia:

$$
\begin{aligned}
& L_{0}=\{0, s,+, \times,<\} \\
& L_{1}=\left\{0, s,+, \times,<, T_{1}\right\} \\
& L_{2}=\left\{0, s,+, \times,<, T_{1}, T_{2}\right\}
\end{aligned}
$$

$$
\vdots
$$

Nesta hierarquia, a partir do estágio 2, um predicado-verdade é introduzido em cada estágio e este funciona como o predicado verdade da linguagem cujo estágio lhe antecede. Assim, $T_{1}$ é o predicado-verdade de $L_{1}, T_{2}$ é o predicado-verdade de $L_{2}$, etc. A interpretação fornecida para $L_{1}$ é a interpretação padrão e, em qualquer estágio $m$, o predicado introduzido nesse estágio (qual seja, $T_{m-1}$ ) deve satisfazer uma versão restrita do Esquema T, ou seja, $T_{m-1}(\ulcorner A\urcorner) \leftrightarrow A$ (para qualquer sentença $A$ de $L_{m-1}$ ).

Note que os requisitos do (LD) continuam disponíveis para todas as linguagens em todos os estágios da hierarquia. Assim, se $\Sigma_{m}$ é o conjunto das sentenças verdadeiras da linguagem $L_{m}$, então, $\Sigma_{m}$ é a extensão do predicado $T_{m}$ em $L_{m+1}$. Pelo (LD), existe uma sentença $G$ de $L_{m}$, tal que,

${ }^{19}$ Para uma apresentação mais detalhada das teorias aqui esboçadas, recomendamos Barrio (2014) e também Cardoso (2018). Uma apresentação mais completa (embora menos detalhada) desta literatura pode ser encontrada no verbete Liar Paradox da Stanford Encyclopedia of Philosophy, escrita por JC Beall, Michael Glanzberg e David Ripley. O texto está disponível no seguinte endereço eletrônico: https://plato.stanford.edu/entries/liar-paradox/. 
$\Sigma_{m} \vdash \neg T_{m+1}(\ulcorner G\urcorner) \leftrightarrow G$, já que $T_{m+1}(x)$ é uma fórmula de $L_{m}$ e $\Sigma$ é uma extensão de $Q$. Pela versão restrita do Esquema $\mathrm{T}$, temos que $\Sigma_{m} \vdash T_{m}(\ulcorner A\urcorner) \leftrightarrow A$, para toda sentença $A$ de $L_{m}$. Neste caso, entretanto, a transitividade da bicondicional não parece mais implicar inconsistência, como antes.

A principal objeção que tem sido apresentada contra as soluções hierárquicas é que elas parecem impedir qualquer aproximação ou espelhamento dos aspectos essenciais da linguagem natural por parte das linguagens formais. Citando Tarski:

Um traço característico da linguagem coloquial (ao contrário de várias linguagens científicas) é sua universalidade. Não estaria em harmonia com o espírito desta linguagem se, em alguma outra linguagem, ocorresse uma palavra que não pudesse ser nela traduzida. Poder-se-ia alegar que 'se podemos falar de modo significativo sobre alguma coisa que seja, também podemos falar a respeito dela na linguagem coloquial (TARSKI, [1935], 2006, p.32).

O poder expressivo da linguagem natural parece ser, de fato, uma de suas características essenciais. Como disse uma vez Millôr Fernandes: "se uma imagem vale mais do que mil palavras, então diga isto com uma imagem". Por outro lado, como vimos, linguagens de primeira ordem classicamente interpretadas e semanticamente fechadas são inconsistentes. Isto parece indicar que todos os modos consistentes de se preservar o poder expressivo da linguagem natural envolvem necessariamente a adoção de interpretações não clássicas.

As abordagens não clássicas dos paradoxos consistem em tentativas de evitar os paradoxos por meio de ajustes em relação à lógica clássica. Vamos falar muito brevemente de apenas dois tipos de soluções não clássicas, aquelas que admitem lacunas de valores-verdade (truth-value gaps) e aquelas que admitem aglutinações de valores-verdade (truth value gluts).

Os defensores de lacunas (gaps) alegam que uma teoria que espelha o conceito ordinário de verdade deve admitir que algumas sentenças não possuem valor de verdade, não são verdadeiras nem falsas. Tomemos como exemplo o Mentiroso Simples, a sentença (1) que diz de si mesma que ela é falsa. Assim, (1) é verdadeira sse (1) é falsa. O problema parece presumir que (1) 
possua valor de verdade. Se recusarmos este pressuposto, o paradoxo inicialmente parece desaparecer. Como vimos, esta ideia precisa ser cuidadosamente detalhada, pois a mera adoção de lacunas resolve o Mentiroso Simples sem resolver o Mentiroso Reforçado.

Em seu trabalho especialmente importante sobre lacunas, Kripke (1975) mostrou que uma teoria de primeira ordem pode satisfazer os requisitos do (LD) e conter seu próprio predicado de verdade, desde que este predicado seja apenas parcialmente interpretado. Assim, na teoria de Kripke, $T$ é interpretado parcialmente, a partir dos conjuntos $\Gamma_{1}$ (a extensão de $T$ ) e $\Gamma_{2}$ (a antiextensão de $T$ ). Esta interpretação deve ser consistente, ou seja, $\Gamma_{1} \cap \Gamma_{2}$ é vazio. Além disso, se esta interpretação vai de fato garantir que a teoria em questão contenha seu próprio predicado verdade, a extensão de $T$ deve coincidir com o conjunto de sentenças verdadeiras da linguagem da teoria e a anti extensão de $T$ deve coincidir com o conjunto das sentenças falsas da linguagem da teoria.

Para cada par $\left(\Gamma_{1}, \Gamma_{2}\right)$ que adotamos como interpretação de $T$, obtemos um modelo da linguagem em questão e, consequentemente, um par $\left(\Delta_{1}, \Delta_{2}\right)$, correspondente aos conjuntos das sentenças verdadeiras e falsas da linguagem em questão na interpretação dada. Isto também depende do esquema de interpretação que estamos utilizando para os símbolos lógicos. Cada esquema de interpretação vai determinar um operador $J$ definido sobre pares $\left(\Gamma_{1}, \Gamma_{2}\right)$ de conjuntos de sentenças da linguagem. $J\left(\Gamma_{1}, \Gamma_{2}\right)=\left(\Delta_{1}, \Delta_{2}\right)$ sse $\Delta_{1}$ é o conjunto de sentenças que resultam verdadeiras na interpretação $\left(\Gamma_{1}, \Gamma_{2}\right)$ e $\Delta_{2}$ é o conjunto das sentenças que resultam falsas na interpretação $\left(\Gamma_{1}, \Gamma_{2}\right) .{ }^{20}$ Nestes termos, o fechamento semântico, para Kripke, consiste em uma interpretação que atribua um par $\left(\Gamma_{1}, \Gamma_{2}\right)$ a $T$, tal que $J\left(\Gamma_{1}, \Gamma_{2}\right)=\left(\Delta_{1}, \Delta_{2}\right)$. Tais interpretações são também chamadas de pontos fixos. (Vamos nos restringir aos pontos fixos consistentes).

\footnotetext{
${ }^{20}$ Mais precisamente, a interpretação $\left(\boldsymbol{\Gamma}_{1}, \boldsymbol{\Gamma}_{2}\right)$ é a extensão do modelo padrão da linguagem em questão pela inclusão de $\boldsymbol{\Gamma}_{1}$ como extensão de $T$ e $\boldsymbol{\Gamma}_{2}$ como antiextensão de $T$, de acordo com o esquema de interpretação associado a $\mathbf{J}$.
} 
Como veremos, pontos fixos consistentes terão de ser interpretações parciais. O par $\left(\Gamma_{1}, \Gamma_{2}\right)$ é uma interpretação parcial sse $\Gamma_{1} \cup \Gamma_{2} \neq S$, onde $S$, é o conjunto das sentenças da linguagem em questão. Na medida em que vamos admitir interpretações parciais, precisamos adotar esquemas não clássicos de interpretação dos símbolos lógicos. Diferentes esquemas poderiam ser utilizados aqui. A única restrição é que tais esquemas devem preservar a monotonicidade sobre as interpretações de $T$. Grosso modo, isto quer dizer o seguinte: seja $J\left(\Gamma_{1}, \Gamma_{2}\right)=\left(\Delta_{1}, \Delta_{2}\right)$ e $J\left(\Gamma_{3}, \Gamma_{4}\right)=\left(\Delta_{3}, \Delta_{4}\right)$. Assim, $J$ é um operador monotônico sse $\Gamma_{1} \subseteq \Gamma_{3}$ e $\Gamma_{2} \subseteq \Gamma_{4}$ implica que $\Delta_{1} \subseteq \Delta_{3}$ e $\Delta_{2} \subseteq \Delta_{4}{ }^{21}$

Kripke mostrou que os operadores monotônicos possuem pontos fixos e, portanto, que existem interpretações parciais que estendem a interpretação padrão da linguagem da Aritmética para uma linguagem que, de certo modo, contém seu próprio predicado-verdade. A rigor, a existência de lacunas inviabiliza a validade irrestrita do Esquema T. Podemos, entretanto, manter o esquema na forma inferencial. ${ }^{22}$

Os modelos de Kripke fornecem ainda uma ferramenta técnica que permite representar importantes distinções entre as sentenças autorreferenciais exploradas na segunda seção, como as sentenças infundadas, as sentenças paradoxais, os mentirosos contingentes e as sentenças up for grabs. Grosso modo, as sentenças infundadas são aquelas que não pertencem ao ponto fixo mínimo. As sentenças paradoxais são aquelas que pertencem a nenhum ponto fixo (como as sentenças (1) a (5) e (9), colocadas na segunda seção). Algumas sentenças infundadas não são paradoxais, como o truth teller (8). Note ainda que as sentenças (6) e (7) são autorreferenciais, mas nada impede que elas se-

\footnotetext{
${ }^{21}$ Kripke não privilegia um esquema monotônico particular, mas apresenta algumas diferenças entre adotar três esquemas muito importantes: Kleene Forte, Kleene Fraco e as Sobrevalorações. Explorando os diferentes pontos fixos obtidos por estes diferentes esquemas, Kripke pôde traçar importantes características das sentenças mentirosas. O esquema forte de Kleene $\left(\mathrm{K}_{3}\right)$, formulado em Kleene (1952), desempenha papel especial na teoria. Para uma breve compreensão deste esquema (seu fragmento proposicional), considere as seguintes regras: i) Negação: $\neg A$ é verdadeira sse $A$ é falsa. $\neg A$ é falsa sse $A$ é verdadeira. De outro modo, $A$ não tem valor. ii) $A \vee B$ é verdadeira sse $A$ é verdadeira ou $B$ é verdadeira. $A \bigvee B$ é falsa sse $A$ e $B$ são falsas. De outro modo, $A \vee B$ não tem valor.

${ }^{22}$ Afinal, se $A$ não tem valor, então $T(\ulcorner A\urcorner)$ não tem valor. Neste caso, em $\mathrm{k}_{3}, T(\ulcorner A\urcorner) \leftrightarrow A$ também não tem valor. Não obstante, $\mathrm{M}$ é modelo de $T(\ulcorner A\urcorner)$ sse $\mathrm{M}$ é modelo de $A$. Podemos também expressar a forma inferencial do Esquema T com as Regras T. i) Introdução de T: $A$ implica logicamente $T(\ulcorner A\urcorner)$, ii) Eliminação de T: $T(\ulcorner A\urcorner)$ implica logicamente $A$.
} 
jam incluídas na extensão de $\mathrm{T}$ em certos pontos fixos e isso não parece arbitrário (como o valor de (8) nos modelos em que tem valor). Finalmente, o valor de (9) depende de fatos contingentes. Se, de acordo com o modelo adotado, existe vida em Trappist-1, então (9) é infundada neste modelo. Se não existe vida em Trappist-1, (9) é falsa neste modelo.

A principal objeção frequentemente levantada às lacunas é que tais abordagens parecem deixar livre o caminho para o Problema da Vingança. Este problema, de certo modo, também parece denunciar perda de poder expressivo das teorias. Vejamos informalmente o argumento que leva a ele.

Suponha que $\Sigma$ é uma teoria de primeira ordem que satisfaz os requisitos do (LD), é parcialmente interpretada (pelas regras de $K_{3}$ ) e contém um predicado $T$ que valida as Regras $T$. Neste caso, (LD) garante a existência de sentenças mentirosas, mas isto não leva a paradoxos, pois estas sentenças não estão nem na extensão nem na anti extensão de $T$. Podemos ver, do lado de fora de $\Sigma$, que ela é livre de paradoxos, mas não podemos expressar isso em $\Sigma$. Se (1) não possui valor de verdade, $T(1)$ e $\neg T(1)$ também não possuem valor de verdade, então não podemos tornar verdadeira a sentença que diz que (1) não é verdadeira. Suponha que adicionássemos à linguagem de $\Sigma$ o predicado $\operatorname{Gap}(x)$ verdadeiro de todas e somente as lacunas (i.e., as sentenças nem verdadeiras nem falsas). Ora, neste caso, (LD) nos permitiria obter uma sentença $G$ 'que diz de si mesma que ela é falsa ou lacuna (aplicamos o lema à fórmula $\neg T(x) \vee \operatorname{Gap}(x)$ ). Estamos de volta com os paradoxos, pois se $G^{\prime}$ é uma lacuna, então $G^{\prime}$ é verdadeira, se $G^{\prime}$ é falsa, ela é verdadeira, mas se $G^{\prime}$ é verdadeira, então, é falsa ou lacuna. Kripke (1975) reconheceu o problema da vingança como um limite para o seu próprio método, nas suas palavras:

(...) as sentenças do Mentiroso não são verdadeiras na linguagem objeto, no sentido de que o processo indutivo nunca as torna verdadeiras; mas estamos impedidos de dizer isso na linguagem pela nossa interpretação da negação e do predicado verdade. Se nós pensarmos no ponto fixo mínimo, digamos sob a valoração de Kleene, como dando um modelo da linguagem natural, então o sentido em que nós podemos dizer, em linguagem natural, que a sentença do mentiroso não é verdadeira deve ser pensada como associada com algum estágio posterior no desenvolvimento da linguagem natural, em que o falante reflete sobre o processo de geração conduzindo ao ponto fixo mínimo. Isso não é em si mesmo parte do processo. A necessi- 
dade de ascender a uma metalinguagem pode ser uma das fraquezas da presente teoria. O fantasma da hierarquia de Tarski ainda está conosco (KRIPKE, 1975, p. 714).

Tendo isso em vista, o poder expressivo próprio da linguagem natural coloca limites em uma abordagem de lacunas para lidar com o Mentiroso. Se pretendemos, de algum modo, lidar com as características intuitivas da linguagem natural, uma abordagem de lacunas parece não ser adequada a esse programa.

Teóricos dialeteístas, como Graham Priest, sustentam que o dialeteísmo supera o problema da vingança, não sofrendo limitações de expressividade. $\mathrm{O}$ custo para conquistar o poder expressivo estaria justamente em assumir aglutinações (gluts).

Dialeteísmo é a visão de que há contradições verdadeiras (dialeteias). $\mathrm{Na}$ perspectiva dialeteísta, a resiliência do Mentiroso diante dos tratamentos consistentes estaria mostrando justamente que há contradições verdadeiras e que, portanto, o dialeteísmo é o tratamento adequado para o paradoxo. Nessa abordagem, a sentença do mentiroso resulta verdadeira e falsa (uma aglutinação). Para defender esse ponto, normalmente é empregado o caráter semanticamente fechado da linguagem natural e a alegação de que a maioria das tentativas de impedir a contradição viola algum recurso intuitivo das línguas naturais que leva ao paradoxo. Como o paradoxo surge na linguagem natural, a partir de recursos básicos, tratar o Mentiroso, na perspectiva dialeteísta, é assumir que há contradições verdadeiras.

De maneira geral, tais paradoxos como o Mentiroso fornecem alguma evidência para a tese dialeteísta que algumas contradições são demonstravelmente verdadeiras, no sentido que elas são implicadas por fatos manifestos sobre as línguas naturais e nossos processos de pensamentos. Os paradoxos do Mentiroso estendido como 'Esta sentença não é verdadeira' são expressáveis no português ordinario. Suas características paradoxais, como os dialeteístas salientam, são devidas justamente às características intuitivas da linguagem ordinária (PRIEST, BERTO, WEBER, 2018, p. 20).

Segundo Priest (2006, p. 24), a consistência da linguagem natural só pode ser adquirida ao diminuir a sua capacidade expressiva de algum modo. 
Assim, com base no fenômeno da vingança, um argumento a favor do dialeteísmo pode ser estabelecido através do seguinte dilema:

D1: qualquer teoria da verdade em uma determinada língua natural será incompleta ou aglutinada (glutty).

O dilema colocado por meio da disjunção é demonstrado a partir do próprio Mentiroso. Ou evitamos a força expressiva da linguagem, impedindo o Mentiroso (e, portanto, a aglutinação), ou permitimos toda expressividade e derivamos o Mentiroso. No primeiro caso, a teoria é incompleta em sua força expressiva e a disjunção vale. No segundo caso, ao permitir toda capacidade expressiva da linguagem, temos meios para construir o Mentiroso e, assim, a disjunção também vale. Dessa forma, de acordo com os argumentos de Priest, devemos aceitar o dialeteísmo. Na visão de Priest, a completude expressiva é adquirida por um preço não tão difícil de pagar: aglutinações. Levando em consideração esse argumento, a teoria de aglutinações decorre da promessa de completude expressiva.

O dialeteísmo afirma que algumas contradições são verdadeiras, mas não que tudo é verdadeiro. Assim, uma lógica paraconsistente deve ser adotada para evitar a trivialidade, restringindo o (PE). Priest (1979) concebe uma lógica, intitulada Lógica do Paradoxo (LP) que, segundo ele, é adequada para modelar contradições verdadeiras, como a do Mentiroso, sem trivialidade. LP tem sentenças que são "somente verdadeiras", "somente falsas" e "verdadeiras e falsas" (aglutinações). A atribuição de valores de verdade é dada a partir de uma função do conjunto das fórmulas atômicas no conjunto de valores de verdade, e é estendida para todas as fórmulas a partir do comportamento dos conectivos dados pelas tabelas de $K_{3}$. Diferentemente de $K_{3}$, onde o terceiro valor é interpretado como uma lacuna, em LP o terceiro valor é interpretado como uma aglutinação. Outra diferença é que em LP o conjunto designado (valores que são preservados em inferências válidas) contém o valor aglutinado, além do verdadeiro.

Em LP, o princípio de explosão (PE) $(A \wedge \neg A \models B)$ não vale irrestritamente. Há modelos que satisfazem $A \wedge \neg A$, mas não satisfazem $B$. Isso 
ocorre quando o valor de $A$ é aglutinado (que é designado) e o valor de $B$ é falso. Note que aqui enunciamos (PE) na forma inferencial e não na forma condicional. Em virtude do TD, clássicamente, todas as verdades lógicas na forma condicional são também teoremas e vice versa. Em LP, a condicional também pode ser definida por meio da equivalência clássica entre $A \rightarrow B$ e $\neg A \vee B$. Assim, o mesmo contra modelo anteriormente apresentado para a forma inferencial de (PE) também invalida (MP) e a forma condicional de (PE) (cf. PRIEST, 2008, cap. 7).

A partir daí, Priest considera que, por meio de aglutinações é possível modelar a contradição do Mentiroso em LP e ainda preservar a força expressiva da linguagem da teoria. Aparentemente, para os que estão dispostos a assumir que há contradições verdadeiras, o dialeteísmo traria algumas vantagens, sobretudo se considerarmos o poder expressivo da linguagem. Todavia, mesmo assumindo contradições verdadeiras, os paradoxos colocam limites para a abordagem dialeteísta. Priest argumenta que o Mentiroso captura a noção de contraditoriedade do quadrado de oposições de Aristóteles. Entretato, se considerarmos o resultado do Mentiroso em LP temos que tanto a sentença do mentiroso quanto a sua negação resultam verdadeiras. Considerando isso, a negação de LP retrataria uma relação de subcontrariedade, como foi apontado por Slater (1995). Ora, se o Mentiroso é entendido como uma contradição (com o sentido de contraditoriedade) e LP tem uma negação com um sentido mais fraco (a subcontrariedade), então LP não seria a lógica adequada para lidar com a contradição do Mentiroso, sem trivialidade. Isso romperia com a promessa dialeteísta de lidar com o Mentiroso. Arenhart e Melo (2017) argumentam que o sentido de contradição como contraditoriedade, encapsulado no Mentiroso, leva à trivialidade, assumindo as próprias exigências do dialeteísmo. Assumindo essa linha de argumentação, a linguagem da teoria dialeteísta não seria capaz de expressar o Mentiroso sem trivialidade.

O paradoxo de Curry também apresenta desafios para a abordagem dialeteísta. Mesmo concedendo que LP captura o sentido de contradição adequado (o que é discutível), lembramos que a estratégia em LP para evitar a trivialidade funciona com base na contradição: tome uma interpretação em 
que $A \wedge \neg A$ é designada e $B$ não designada. Todavia, essa estratégia não impede a trivialidade via paradoxo de Curry que, como vimos anteriormente, leva à trivialidade diretamente, sem a necessidade da contradição. Assim, mesmo invalidando a explosão, o paradoxo de Curry não seria evitado e poderíamos derivar a trivialidade. Priest (2006) lida com esse problema restringindo a regra de contração do condicional (Con). ${ }^{23}$

Todavia, um outro paradoxo do tipo Curry foi colocado, desafiando os limites do dialeteísmo, a partir da noção de validade (conhecido como Curry da validade, ou v-Curry). Uma restrição na condicional material, como foi feita por Priest (2006), não seria suficiente para impedir a trivialidade a partir de v-Curry. Dada uma linguagem semanticamente completa e uma teoria $\Sigma$ nesta linguagem dotada de uma relação de consequência $\vdash$, podemos introduzir um predicado de validade para essa linguagem $\operatorname{val}(\ulcorner A\urcorner,\ulcorner B\urcorner)$ para expressar que $B$ se segue de $A$ em $\Sigma$. Com isso, é possível construir uma sentença $C$ (conhecida como sentença Beall-Murzi) que significa $\operatorname{val}(\ulcorner C\urcorner,\ulcorner\perp\urcorner)$, onde $\perp$ significa "tudo é verdadeiro". A partir de princípios muito razoáveis sobre a validade, Beall (2015) mostra como podemos chegar na trivialidade a partir da sentença $C$.

Assumindo que a linguagem é completa em sua força expressiva, ela irá fornecer ingredientes para a derivação da trivialidade e, se estamos seguindo a mesma linha de raciocínio que Priest estabeleceu para o caso do Mentiroso, (i.e., o argumento da completude expressiva via Mentiroso), devemos endossar a trivialidade, se quisermos manter a completude expressiva e os recursos que levam ao paradoxo disponíveis na linguagem natural. Diante disso, Beall (2015, p.558) estabelece um segundo dilema da seguinte maneira:

D2: qualquer teoria da verdade em uma determinada língua natural será incompleta ou trivial.

Agora, se quisermos evitar a trivialidade, ou devemos evitar a completude expressiva ou algum princípio da linguagem natural que conduz ao para-

${ }^{23}$ Como dissemos, LP invalida (MP), portanto o paradoxo de Curry não é um problema para LP. Entretanto, uma condicional que não valide (MP) está muito longe de capturar as intuições da condicional da linguagem natural. Entretanto, Priest (2006) apresenta uma condicional intensional que valida (MP) e invalida (Con). 
doxo. Ora, mas segundo o argumento a favor do dialeteísmo que vimos acima (com base em D1) devemos preservar a completude expressiva e os demais princípios que levam ao paradoxo (foi esse o argumento dado para aceitarmos aglutinações via paradoxo do Mentiroso). Beall chama D1 e D2 de "disjunções limitativas”. Assim, diante de D1 e D2, Beall (2015, p. 575) diz: “[p]aridade de raciocínio demanda igual tratamento de ambas disjunções limitativas (e a conclusão tirada daí). Mas, então, devemos escolher a incompletude”.

Para evitar a trivialidade, devemos evitar a completude. Com isso, aglutinações perdem a motivação. Aglutinações foram motivadas pela promessa de completude. Agora, sem completude, não temos trivialidade (por conta do v-Curry), mas também não temos aglutinações; isto é, sem sentenças do Mentiroso. Ou seja, se perdemos a completude, perdemos o motivo para aceitar aglutinações. Com isso, o dilema entre completude expressiva e trivialidade parece assombrar o dialeteísmo.

Priest tenta lidar com a situação do v-Curry a partir de um sistema chamado "Dual Bunch Logic" em que ele estabelece dois tipos de conjunções: uma conjunção extensional e um operador de fusão. Não vamos entrar nos detalhes técnicos aqui (para isso, veja PRIEST, 2015). Com esse formalismo, a trivialidade é evitada, mas o operador de fusão colocado para resolver o problema tem pouca conexão com o comportamento da conjunção em línguas naturais. Priest diz que a fusão é um tipo de conjunção que representa uma aplicação funcional que não é nem associativa, nem comutativa e nem contrativa. Porém, Priest não fornece nenhuma relação do operador de fusão com os princípios presentes nas línguas naturais - algo que esperado pelo um dialeteísta, tendo em vista os argumentos para o dialeteísmo via recursos das línguas naturais (cf. PRIEST, 2006, p.09). Além disso, Priest evita a trivialidade com base no seu formalismo, porém ele não oferece nenhuma motivação filosófica ou razão independente para restringir a inferência do v-Curry, além do motivo de que v-Curry leva à trivialidade. Sobre oferecer uma razão independente para restringir o tipo de contração envolvida no v-Curry, Priest (2016, p.94) apenas remete aos trabalhos dos lógicos subestruturais, dizendo que nesses trabalhos podemos encontrar, dentre outras coisas, justificações filosóficas 
para se restringir a contração e, com isso, impedir a derivação do v-Curry. Ocorre que os motivos que poderiam levar à falha do v-Curry, podem levar também à falha do Mentiroso, como bem apontam "os lógicos subestruturais" referidos por Priest (veja, por exemplo, ZARDINI, 2011).

Essa discussão sobre v-Curry no contexto das lógicas subestruturais é vasta e com várias implicações. ${ }^{24} \mathrm{~A}$ partir dessa discussão entre Beall e Priest sobre a validade do v-Curry, Arenhart e Melo (2019) sustentam que os critérios de Priest são alterados a depender das consequências que ocorrem no dialeteísmo. Quando é o Mentiroso que está em jogo, então os recursos que levam ao paradoxos devem estar todos autorizados, sob pena de não termos uma solução natural para o problema. Assim, o paradoxo está autorizado e devemos aceitar o seu resultado: aglutinações. Agora, quando temos um paradoxo que leva à trivialidade diretamente, o critério é modificado, podendo assumir um formalismo que restringe os princípios das línguas naturais que levam ao seu resultado: a trivialidade.

É interessante mencionar que embora Beall se posicione contrariamente ao argumento da completude semântica em favor do dialeteísmo, ele ainda aceita o Mentiroso como uma motivação para aglutinações. Porém, a motivação de Beall para tomar o Mentiroso como uma evidência em favor de aglutinações não consiste em um argumento lógico, e sim em uma consideração estética. A conclusão de Beall é a seguinte:

Devemos rejeitar o argumento alvo a partir da versão da inconsistência-absoluta da disjunção não limitativa e o objetivo da completude para aglutinações. Mesmo se, contrariando as aparências, a paridade de razões não exigir uma resposta igual para um perfeito paralelo da disjunção limitativa, a versões da inconsistência-absoluta da disjunção limitativa põe fim em qualquer promessa de uma teoria completa do português no português; e então a promessa de ter uma tal teoria ao mero custo de aglutinações é uma falsa promessa (BEALL, 2015, p. 580).

Depois dessa conclusão, Beall (2015, p.583) apenas diz que "o tratamento de aglutinações surge a partir de considerações estéticas: tais Mentirosos simplesmente parecem aglutinações". Porém, consideramos que esse

\footnotetext{
${ }^{24}$ Para uma apresentação ampla dos tratamentos subestruturais, ver BEALL, GLANZBERG,\& RIPLEY, 2018, cap. 7).
} 
argumento estético é insuficiente para sustentar o dialeteísmo (para detalhes, ver MELO, 2017). Independentemente da viabilidade do argumento estético, o dialeteísmo padece do mesmo problema de seus rivais consistentes: a falta de força expressiva da teoria e isso é reconhecido mesmo por alguns dialeteístas, como Beall.

\section{Considerações finais}

Como vimos ao longo do artigo, o paradoxo do Mentiroso é um paradoxo importante para a lógica, tendo em vista os resultados técnicos relacionados com tal paradoxo, e para a filosofia da lógica, considerando as abordagens filosóficas sobre o conceito de verdade que surgiram a partir de reflexões sobre o paradoxo do Mentiroso. Neste artigo procuramos fazer uma apresentação sobre o paradoxo do Mentiroso, destacando alguns desses resultados técnicos e filosóficos relacionados com ele. Além disso, procuramos deixar claro que o paradoxo do Mentiroso parece impor limites que são difíceis de acomodar em teorias que pretendem dar conta do predicado-verdade ordinário.

Começamos este texto apresentando o paradoxo do Mentiroso para deixar claro o problema mesmo para os não familiarizados com as discussões sobre paradoxos e teorias da verdade. A partir dessa apresentação foi possível conferir também alguns pressupostos importantes envolvidos no Mentiroso. Como tentamos mostrar, existem versões naturais dos mentirosos apoiadas em premissas que espelham traços aparentemente inelimináveis da linguagem natural e do conceito ordinário de verdade. Tais versões nos colocam diante de um problema filosófico genuíno. Em primeiro lugar, a existência de sentenças autorreferenciais não parece ser considerada consensualmente condição necessária nem suficiente para a derivação dos paradoxos. Além disso, mesmo em algumas teorias formais (aquelas capazes de representar todas as funções recursivas) existem sentenças que espelham a autorreferência. Isto nos levou ao Teorema da Indefinibilidade de Tarski, pelo qual, nenhuma teoria clássica capaz de representar todas as funções recursivas pode (consistentemente) conter o seu próprio predicado-verdade. 
Em segundo lugar, o conceito ordinário de verdade (aquele representado pelo predicado-verdade da linguagem natural) parece satisfazer o Esquema T e é difícil encontrar bons argumentos contra o fechamento semântico da linguagem natural. Ou seja, diferentemente do que dissemos acima sobre certas linguagens e teorias formais, parece difícil recusar que a linguagem natural contenha o seu próprio predicado-verdade. Finalmente, presumimos que o conceito ordinário de verdade seja consistente, não trivial e compatível com a lógica clássica. Ou seja, presumimos que uma teoria da verdade que represente o conceito ordinário de verdade deveria ser uma teoria clássica, consistente e não trivial. Como vimos, as principais tentativas de solução, ainda que avancem importantes resultados para uma melhor compreensão dos mentirosos e dos limites estabelecidos pelo Teorema de Tarski, enfrentam problemas muito semelhantes.

Nas abordagens hierárquicas e nas abordagens com lacunas temos de escolher entre perder poder expressivo ou abrir o caminho para versões mais fortes do Mentiroso. Neste caso, tentamos ao menos preservar a consistência, mas temos de pagar com a perda de expressividade.

De outro lado, as abordagens com aglutinação invertem essa relação, abrem mão da consistência pela recompensa de poder expressivo. Não é claro, entretanto, que a recompensa seja obtida. Como expresso pelos argumentos de Beall (2015), via a paridade de D1 e D2, qualquer teoria da verdade em uma determinada língua natural será expressivamente incompleta ou trivial. Assim, considerando os argumentos de Beall, as abordagens dialeteístas que se pretendam não triviais serão também assombrada pelo fantasma de Tarski, na medida em que não podem pagar a promessa da completude expressiva, mesmo assumindo aglutinações.

Considerando os argumentos que foram desenvolvidos por Arenhart e Melo (2019), indicamos aqui que as abordagens de aglutinações até podem se livrar do fantasma de Tarski, mas, para tanto, terão que enfrentar o fantasma da trivialidade. A contradição envolvida no Mentiroso parece impor limites que variam entre a expressividade e a trivialidade. Esse dilema nos permite afirmar que o paradoxo do Mentiroso diz respeito a um problema genuina- 
mente filosófico que pode pode ser acomodado por nada menos do que um repúdio de parte da nossa herança conceitual, como observado por Quine (1966, p.11).

\section{Referências}

ARENHART, J. R. B. \& MELO, E. S. 'Classical Negation Strikes Back: Why Priest's Attack on Classical Negation Can't Succeed'. Logica Universalis (Print), v. 11, 2017, pp. 465 - 487.

$115-134$.

‘(De)motivating Gluts'. Logique et Analyse, v. 246, 2019, p p.

BARRIO, E. La Lógica de la Verdad. Eudeba Universidad de Buenos Aires, 2014.

BARWISE, J., AND ETCHEMENDY, J. The Liar: an essay on truth and circularity. Oxford, New York, 1987.

BEALL, J.C Revenge of The Liar - New Essays on the Paradox. OUP, New York, 2007.

'Trivializing sentences and the promise of semantic completeness'. Analysis 75(4), 2015 pp.573 - 584.

BEALL, J.C., GLANZBERG, M. \& RIPLEY, D. Formal theories of truth. Oxford: Oxford Un. Press, 2018.

BOOLOS, G., BURGESS, J., AND JEFFREY, R. Computabilidade e Lógica [2007]- Tradução de Cezar Mortari. Unesp, São Paulo, 2012.

BURGE, T. 'Semantical paradox'. Journal of Philosophy. 76, 1979, pp. 169 198.

CARDOSO, G. O Paradoxo do Mentiroso: uma introdução. Coleção CLE, 2018.

FRANKFURT, H. Sobre falar merda. Ed Intrínseca Limitada, 2005.

GLANZBERG, M. 'The liar in context'. Philosophical Studies. 103(3). 2001, pp. $217-251$.

GLANZBERG, M. 'A contextual-hierarchical approach to truth and the liar paradox'. Journal of Philosophical Logic. 33(1), 2004. pp. 27 - 88. 
GRIM, P. The Incomplete Universe: Totality, Knowledge, and Truth. MIT Press, 1991.

HAACK, S. Filosofia das Lógicas [1978]. Trad. Cezar Mortari e Luiz Henrique Dutra. Editora Unesp, 2002.

HECK, R. 'Self-reference and the languages of arithmetic'. Philosophia Mathematica 15(1), 2007, pp. 1 - 29.

KLEENE, S. Introduction to Metamathematics. North Holland Publishing CO., Amsterdam, 1952.

KRIPKE, S. 'Outline of a theory of truth'. Journal of Philosophy. 72, 1975, pp. $690-716$.

MELO, E. S. O paradoxo do Mentiroso: argumentos contra o dialeteísmo. (tese de doutorado). Programa de Pós-Graduação em Filosofia, UFSC. Florianópolis, 2017.

MORTARI, C. Introdução à Lógica. Editora Unesp, 2016.

PARSONS, C. Parsons, C. 'The Liar Paradox”. Journal of Philosophical Logic. 3(4), 1974, pp. $381-412$.

PRIEST, G. 'The logic of paradox'. Journal of philosophical logic. 8, 1979. pp. $219-241$

In Contradiction. Oxford University Press, Oxford, 2006.

An Introduction to Non-classical Logic. Cambridge University Press, Cambridge, 2008.

'Fusion and confusion'. Topoi 34, 2015, pp. 55 - 61.

'Old wine in (somewhat leaky) new bottles. Some comments on Beall'. Australasian Journal of Logic. 13(5), 2016, pp. 89 - 95

PRIEST, G., BERTO, F. and WEBER, Z., 'Dialetheism', The Stanford Encyclopedia of Philosophy (Fall 2018 Edition), Edward N. Zalta (ed.), URL = $<$ https://plato.stanford.edu/archives/fall2018/entries/dialetheism/>.

QUINE, W. The Ways of Paradox and Other Essays. Random House, New York, 1966.

READ, S. [1995] Repensando a lógica: uma introdução à filosofia da lógica Tradução de Abílio Rodrigues. Belo Horizonte: Editora da UFMG, 2016. 
RUSSELL, B. 'Mathematical logic as based on the theory of types'. American Journal of Mathematics. 30, 1908, pp. 222 - 262.

SAINSBURY, R. M. Paradoxes. Cambridge University Press, 2009.

SIMMONS, K. Universality and The Liar: An Essay on Truth and the Diagonal Argument. Cambridge University Press, New York, 1993.

SIMMONS, K. Revenge and context. In BEALL (2007), pp. 345 - 367.

SLATER, B. H. 'Paraconsistent logics?'. Journal of Philosophical Logic. 24. 1995, 451- 454 .

SMULLYAN, R. What is the name of this book? Prentice-Hall Inc, New Jersey, 1978.

TARSKI, A. [1935] 'O conceito de verdade nas linguagens formalizadas' Tradução de Cezar Mortari. In A Concepção Semântica da Verdade - Textos Clássicos de Tarski, [Orgs.: Cezar Mortari; Luiz Dutra]. Unesp, São Paulo, 2006, pp. $19-148$.

[1944] 'A concepção semântica da verdade e os fundamentos da semântica'. Tradução de Luiz Dutra. In A Concepção Semântica da Verdade Textos Clássicos de Tarski, [Orgs.: Cezar Mortari; Luiz Dutra]. Unesp, São Paulo, 2006, pp. 157 - 201.

[1969] 'Verdade e demonstração'. Tradução de Jesus de Paula Assis In A Concepção Semântica da Verdade - Textos Clássicos de Tarski, [Orgs.: Cezar Mortari; Luiz Dutra]. Unesp, São Paulo, 2006 pp. 203 - 233.

TARSKI, A., MOSTOWSKI, A., AND ROBINSON, R. Undecidable Theories. North Holland Publishing Company, Amsterdam, 1953.

VAN FRAASSEN, B. C. 'Pressuposition, implication and self-reference'. Journal of Philosophy 65(5) (1968), pp. 136-152.

YABLO, S. 'Paradox without self-reference'. Analysis. 53-4, 1993, pp. 251 252.

ZARDINI, E. 'Truth without contra(di)ction'. The Review of Symbolic Logic. 4(4), 2011, pp. 498 - 535. 